\title{
The effects of molecular flexibility and substituents on conformational polymorphism in a series of 2,5-diamino-3,6-dicyanopyrazine dyes with highly flexible groups
}

Authors: Yoko Akune ${ }^{1}$, Haruyuki Gontani ${ }^{1 \dagger}$, Risa Hirosawa ${ }^{1}$, Atsushi Koseki ${ }^{1 \ddagger}$, Shinya Matsumoto ${ }^{1}$

1. Graduate School of Environmental and Information Sciences, Yokohama National University, 79-7

Tokiwadai, Hodogaya-ku, Yokohama 240-8501, Japan.

${ }^{\dagger}$ Present address: R\&D Division, Kansai Paint Co., Ltd., 17-1, Higashi-Yawata 4-chome, Hiratsuka, Kanagawa 254-8562, Japan.

$\ddagger$ Present address: R\&D Division, Toyocolor Co., Ltd., 400, Tenma, Fuji City, Shizuoka, 419-0205, Japan.

\begin{abstract}
Conformational polymorphism of a series of 2,5-bis( $N, N$-dibenzylamino)-3,6-dicyanopyrazine dyes, with high molecular flexibility in a non-hydrogen-bonding system, is described. Three derivatives having a substituent at the 4-position of the benzyl groups exhibited several crystal forms with different colours (red, orange, and yellow), whereas a single form was found in the unsubstituted benzyl derivative and the derivative containing 2-naphthylmethyl groups. The effects of conformational flexibility and the substituents on conformational polymorphism were evaluated through structural, energetic, and statistical analyses based on all of the observed crystal structures. They were divided into four conformational groups according to their conformational similarities, and the major difference among the groups was attributed to the amino geometry. Statistical research using the Cambridge Structure Database suggested that a dibenzylamino group connected to an aromatic ring had a suitable potential surface for the occurrence of conformational polymorphs, and had at least two potential wells with respect to the amino geometry. This result revealed that the flexibility of the dibenzylamino group in the pyrazine derivatives enabled the formation of various molecular shapes. However, the preference of occurrence of polymorphs was different in these derivatives. Crystal structure analysis indicated that the similarity in the molecular shapes was significant for the closed packing in the thermally stable forms, whereas the terminal substituents on the dibenzyl groups played an important role in the crystal structures of the thermally metastable forms via the formation of weak interactions such as halogen interactions.
\end{abstract}

\section{Keywords}

Conformational polymorphism, color change, conformational potential surface, lattice energy calculation, substituents effect 
${ }^{*}$ Corresponding author. Tel +81-45-339-3366; Fax +81-45-339-3345. E-mail address: smatsu@ynu.ac.jp (Shinya Matsumoto). 


\section{Introduction}

Polymorphism is a phenomenon in which a compound adopts two or more crystal structures [1]. The phenomenon has attracted much interest in academic and industrial research. The differences in packing arrangements and molecular conformations among polymorphs lead to different physicochemical properties in the crystalline state. Chloramphenicol palmitate, an important antibiotic, was found to exhibit three polymorphs [2]. The bioavailability of these polymorphs was dependent on the solubility in these crystal forms [3]. The occurrence of polymorphs has an impact on research and manufacturing activities in industries such as the pharmaceutical, food, and pigment industries [4]. It is important to predict the occurrence of polymorphs based on molecular structure for material design and to gain an understanding of polymorphism. However, determination of the crystal structures of metastable polymorphs through computational prediction has been considered difficult, particularly in a flexible molecule [5]. The structural factors which favour polymorphism, such as conformational flexibility and hydrogen bonding, remain essential for predicting the occurrence of polymorphs [6]. When polymorphism results from the different conformations of the same molecule, it is termed conformational polymorphism [7]. 5-Methyl-2-[(2-nitrophenyl)amino]-3-thiophenecarbonitrile, also known as ROY, is a well-known compound which exhibits seven crystal forms with various conformations [8]. Although conformational polymorphism requires molecular flexibility, a flexible molecule does not always exhibit conformational polymorphism [9]. Cruz-Cabeza and Bernstein pointed out that the differences in conformations in conformational polymorphs should be caused by differences in the conformational potential wells on the conformational energy surface of a molecule in the gas phase [7c]. Their statement indicated that the occurrence of conformational polymorphism would require a specific level of molecular flexibility which has several potential wells on the conformational energy surface in the gas phase.

Lutker and colleagues have recently introduced the concept of a polymorphophore, defined as "a structural element that, when incorporated into a molecule, favours the formation of polymorphic crystal forms” [10]. The fenamate fragment (from 2-(phenylamino)benzoic acid, fenamic acid) is a well-known polymorphophore [11]. In tolfenamic acid, (2-[(3-chloro-2-methylphenyl)amino]benzoic acid, a member of the fenamate group), five crystal forms have been characterised, whereas a single form was found in fenamic acid. Using the calculated crystal energy landscape, Uzoh and colleagues revealed that the variety of crystal structures of tolfenamic acid was caused by the steric effects of the $\mathrm{Cl}$ atom and methyl group on the phenyl group [12]. This result indicated that the substituents, as well as the specific molecular flexibility, are an important factor for the occurrence of conformational 
polymorphs. The occurrence of conformational polymorphs in several other compounds was also affected by subtle differences in their substituents [13]. However, the effect of substituents on the occurrence of conformational polymorphs has not been sufficiently studied in a compound which does not form a typical hydrogen bond in the crystal structure.

We previously reported that a series of 2,5-bis[ $N, N$-di-(halogenophenyl)methylamino]-3,6dicyanopyrazine dyes $(3,4,6,7)$ (Fig. 1) exhibit a colour-polymorphism with different conformations [14], although these derivatives were not expected to form typical hydrogen bonds. These derivatives were composed of a rigid chromophore (pyrazine ring with amino nitrogens and cyano groups) [15] and flexible dibenzyl groups on the amino moieties. The torsional flexibility of the dibenzyl groups contributed to the emergence of the various conformations. In addition, subtle differences in the terminal substituents on the dibenzyl groups would cause a change in the occurrence of the polymorphs. In this work, we analysed the crystal structures of a series of 2,5-diamino-3,6-dicyanopyrazine derivatives with unsubstituted benzyl groups (1), para-substituted dibenzyl groups (2-4), and 2naphthylmethyl groups (5) (Fig. 1) to evaluate the effect of flexibility and substituents on the conformational polymorphism in this non-hydrogen-bonding system. The effect of flexibility on the occurrence of the conformational polymorphs was examined via conformational analysis based on conformational similarity. In addition, the conformational potential surface of the dibenzylamino group was statistically estimated using the conformational preference in the Cambridge Structure Database (CSD). The effect of the substituents on the benzyl groups on crystal stability was evaluated through structural (short-contact) and energetic (lattice energy) analyses.

[Fig. 1]

\section{Experimental}

\subsection{Materials}

Derivatives 1-5 were supplied by Nippon Soda Co. Ltd., and the details of the synthetic procedure are described elsewhere $[14,15]$.

\subsection{Crystallisation}

The eleven crystal forms of derivatives $\mathbf{1 - 5}$ were obtained from several solvents at room temperature (see Fig. 2 and Table S1). These forms were abbreviated as 10, 2Y, 2R, 3Y, 3YO, 3O, 3R, 3RV, 4Y, 4O, and 5O, where R, RV, O, YO, and $Y$ represent the colours of the crystals: red, red violet, orange, 
yellowish orange, and yellow, respectively. The crystal of $\mathbf{1 0}$ of X-ray diffraction quality was crystallised from the solvent combination of $\mathrm{CHCl}_{3} / n$-hexane in the first crystallisation experiment, although any crystals of derivative $\mathbf{1}$ of X-ray diffraction quality could not be obtained in the subsequent many experiments. $\mathbf{2 Y}$ and $\mathbf{2} \mathbf{R}$ were crystallised concomitantly from the solvent combination shown in Table S1. We observed that $\mathbf{R R V}$ was always crystallised concomitantly with 3Y, while $\mathbf{3 Y}$ was crystallised from several conditions without $\mathbf{3 R V}$. The crystal of $\mathbf{3 R}$ was gained only when using $n$-hexane as a poor solvent. We obtained only one crystal of 3YO of X-ray diffraction quality from the solvent combination of $\mathrm{CHCl}_{3} /$ ethanol for once. Other single crystals or powders of $3 Y O$ have never been obtained in the subsequent many experiments. Slow evaporation of benzene solution of the derivatives $\mathbf{3}$ and $\mathbf{4}$ frequently led to the crystal of $\mathbf{3 0}$ and $\mathbf{4 0}$, respectively. The crystals of $\mathbf{4 Y}$ and $\mathbf{5 O}$ of $\mathrm{X}$-ray diffraction quality were obtained by the solvent combinations shown in Table S1. Both $\mathbf{4 Y}$ and $\mathbf{5 O}$ were also found to obtain from any other solvents or solvent combinations. The crystal structures of $\mathbf{3 Y}, \mathbf{3 R}$, and $\mathbf{4 Y}$ have been previously reported [14]. The $\mathrm{X}$-ray diffraction measurements were performed on the following five forms: 10, 2Y, 2R, 3YO, and 5O. Crystals of 3RV, 30, and 40 of X-ray diffraction quality could not be obtained despite many efforts.

[Fig. 2]

\subsection{X-ray crystallography}

The diffraction data for the novel five forms (10, 2Y, 2R, 3YO, and 50) were collected at $296 \mathrm{~K}$ on a Rigaku R-AXIS Rapid imaging plate area detector with graphite-monochromated $\mathrm{CuK} \alpha$ radiation (50 kV, 40 mA, $\omega$-scans). An empirical absorption correction was applied using RAPID-AUTO [16]. The data were corrected for Lorentz and polarisation effects.

Structure solution and refinement were performed using SHELX-97 and SHELXL-97 [17]. All nonhydrogen atoms were anisotropically refined by full-matrix least-squares refinement based on $F^{2}$. Hydrogen atoms in the five forms were located at the calculated positions and refined using the riding model. The publication materials were generated using CrystalStructure 4.0 [18]. ORTEP diagrams of each form were drawn with 50\% ellipsoid probability by Mercury 3.3 [19].

Although the values of data completeness for 10 and 3 YO were 0.920 and 0.927, respectively, we considered these data appropriate for the comparison with the crystal structures of the other forms because their $R$-values were sufficient ( $R_{1}$ values were $7.44 \%$ and $6.50 \%$, respectively). Another 
crystal of these forms in X-ray diffraction quality for further measurements could not be obtained because these forms were difficult to reproduce under the possible experimental conditions, particularly 3YO, which may have been a “disappearing polymorph” [20].

\subsection{Calculations of conformational similarity and conformational energy}

Conformational similarity was evaluated using the Molecule Overlay module of Mercury 3.3. Similarity was determined by the root mean square deviation (RMSD) of distance between two molecular conformations. The comparison between the different conformations was limited to the same compound in this module; thus, each terminal substituent on the benzyl groups in derivatives 2 5 was converted to a hydrogen atom without changing the molecular shape. Then, the molecular conformations of the modified molecular geometries were compared.

Conformational energy was calculated by density functional theory [21] using Gaussian 09 at the $\omega B 97 X-D / 6-31 G(d)[22]$ level of theory. Single-point energy calculation was carried out using the atomic coordinates obtained by X-ray analysis. The hydrogen atom positions were normalised in all calculations.

\subsection{Evaluation of intermolecular interactions}

Intermolecular interactions in the observed crystal structures were evaluated through the short contacts. The short contacts were defined as those that are shorter than the sum of van der Waals radii. The hydrogen atom positions were corrected using the averaged value from neutron diffraction measurements.

The lattice energy and the energy of the molecular pairs in the crystal structure were calculated using the atom-atom Coulomb-London-Pauli (AA-CLP) model, a computer program package for the empirical calculation of intermolecular interactions and crystal energy developed by Gavezzotti [23]. The AA-CLP calculation was performed using the atomic coordinates in the crystal structure and the atomic point charge calculated by the natural population analysis using the $\omega$ B97X-D/6-31G(d) level of theory.

Hirshfeld surface analysis was also carried out with CrystalExplorer [24]. The calculation was performed using the atomic coordinates in the crystal structure.

\subsection{Observation of thermal phase transition}


Phase transitions among polymorphs were observed using a Mettler FP2 hot stage. Each crystal form was placed on a microscope slide and set on the hot stage. The heating rate was $10 \mathrm{~K} / \mathrm{min}$.

In addition, differential scanning calorimetry (DSC) was conducted in crimped aluminum pans using a Rigaku Thermo plus2 DSC8230 at heating rate of $10 \mathrm{~K} / \mathrm{min}$. Before the DSC measurement, each powder sample was characterised by powder X-ray diffraction which was carried out by the same equipment and setting as single crystal X-ray diffraction (see section 2.3).

\subsection{Conformational flexibility of the dibenzylamino group in the CSD}

We performed a search in the CSD (version 5.35 with updated data added on November 13) using ConQuest [25] to estimate the incidence of polymorphism in compounds containing one or more dibenzylamino groups. The search was carried out using our target fragment shown in Fig. 3 in order to extract the compounds containing one or more dibenzylamino groups and their analogues from the CSD. This search covered the compounds containing the elements $\mathrm{C}, \mathrm{H} / \mathrm{D}, \mathrm{N}, \mathrm{O}, \mathrm{S}$, and $\mathrm{P}$, and halogens. Compounds with determined 3D coordinates were included in the search, whereas polymeric compounds, ions, and multi-component crystals such as solvates were excluded. The dibenzylamino pyrazine derivatives in the CSD were also excluded. The search results were used to estimate the incidence of polymorphism. Then, we selected high-quality structural data to evaluate the geometrical features in the search results. The results in which the $R$ factor was less than $10.0 \%$ were selected. The crystal structures with errors and/or disorder were excluded. The structures determined by powder patterns were also excluded. These search results were divided into three groups according to the type of covalent bond between $X$ and $Z$ represented by the dotted line in Fig. 3. The three types of covalent bond were a single bond, a non-aromatic double bond, and an aromatic double bond. No compound featured an $X$-Z triple bond. In ConQuest, the chemical diagrams registered in the CSD were used to identify the bond types.

Polymorphism in the compounds of the search results was determined through the following steps. First, the search results were sorted by CCDC refcode because each compound has a unique refcode regardless of the differences in crystal structures. The compounds with the same refcodes were extracted. Second, comparison between crystal structures assigned the same refcode was carried out using the Crystal Packing Similarity module of Mercury 3.3. Finally, polymorphism was determined based on the RMSD between two crystal structures and the powder pattern similarity. In cases where the determination using the two calculated parameters was difficult, lattice parameters were used. 
We estimated a pyramid cone angle and torsion angles around the amino group in order to evaluate the geometrical features in the high-quality structural data of the search results. The pyramid cone angle, defined as the sum of the three angles around the amino nitrogen of the target fragment, was calculated. The torsion angles around the amino nitrogen (see Fig. 3, $a-b-c-d$ or $a-b-c^{\prime}-d$ ') were also extracted from the selected search results to evaluate the relative locations of the phenyl rings on the target fragment. Point $b$ of the torsional angle was the centre of the least squares plane defined by the three carbons of the amino group. In Fig. 3, the amino geometry whose pyramid cone angle is larger than $348^{\circ}$ was characterised as displaying $\mathrm{sp}^{2}$-like hybridisation. The number of calculated geometrical features was greater than the number of compounds contained in the search results because the geometrical features were calculated per geometry. When the compound has two or more target fragments and/or two or more molecules in an asymmetric unit, the compound has two or more geometrical sites.

\section{[Fig. 3]}

\section{Results and discussion}

\subsection{Crystal data obtained by $\mathrm{X}$-ray analysis}

The novel five crystal forms $(\mathbf{1 0}, \mathbf{2 Y}, \mathbf{2 R}, \mathbf{3 Y O}$, and $\mathbf{5 0})$ were added to the pyrazine colourpolymorphic group in this study. Derivatives $\mathbf{2}$ and $\mathbf{3}$ exhibited conformational polymorphism. All new structures were solved in the monoclinic space group, and the molecule in each form occupied a centrosymmetric position in a crystal, except for 10, which had one molecule in the asymmetric unit. The crystal data, including previously reported structures (3Y, 3R, and $\mathbf{4 Y}$ ) [14], are summarised in Table 1.

[Table 1]

\subsection{Molecular structures of derivatives 1-5}

The chromophore composed of a pyrazine ring with amino nitrogens and cyano groups adopted a planar geometry in all of the molecular conformations of the observed crystal structures. The flexibility of the dibenzylamino groups contributed to the appearance of the various conformations. Their molecular conformations had structural similarities depending on the crystal colours despite having 
different substituents on the benzyl groups (Fig. 4). The molecular conformations of the observed crystal forms were divided into four groups based on the conformational similarity (Table S2). The first group (Group A) included two red forms, 2R and 3R. The amino groups of these red forms had trigonal geometry; thus, the hybridisation of the amino nitrogen was considered $\mathrm{sp}^{2}$-like. The second group (Group B) included four forms: 2Y, 3Y, 4Y, and 5O. The amino groups of these forms had tetragonal geometry, and the hybridisation of the amino nitrogen was considered $\mathrm{sp}^{3}$-like. The third group (Group C) included only one form, 10, which had both $\mathrm{sp}^{2}$-like and $\mathrm{sp}^{3}$-like hybridisation in a molecule. The fourth group (Group D) included one form, 3YO. Like the forms in Group B, this form had $\mathrm{sp}^{3}$-like hybridisation, although the location of the phenyl rings in $\mathbf{3 Y O}$ was significantly different from those in the four forms in Group B. Table 2 shows the significant molecular geometries in all of the molecular conformations. These findings implied that the amino geometry of the dibenzylamino group was essential to their molecular conformations.

\section{[Table 2]}

[Fig. 4]

\subsection{The flexibility of the dibenzylamino groups in statistical analysis}

The torsional flexibility of the dibenzylamino groups contributed to the variations in the conformations of these pyrazine derivatives. A compound containing the dibenzylamino group would favour conformational polymorphism. We performed a search of compounds with the target fragment containing a dibenzylamino group and its analogues in the CSD to estimate the effect of the molecular flexibility of the target fragment on polymorphism. Among 381 organic compounds found, five had polymorphs $(0.8 \%$, Table S3), while the other compounds with the target fragment did not exhibit polymorphism despite their high molecular flexibility. In organic compounds, the incidence of polymorphism has been known to be more than several percent [5b, 26]. In the case of compounds in which the target fragment is substituted by an aromatic ring in the search results, the incidence of polymorphism was estimated to be $6 \%$ (Table S4). This result implied that the flexibility which favours polymorphism would satisfy an appropriate electronic and/or structural condition.

Fig. 5a shows the distribution of the pyramid cone angle around the amino nitrogen of the target fragment. The hybridisation of the amino nitrogen of the target fragment was affected by the bonding environment around the amino group. When the covalent bond between $Z$ and $X$ represented by the 
dotted line in Fig. 3 was a single bond, the hybridisation of the amino nitrogen was characterised as $\mathrm{sp}^{3}$-like (the blue bar in Fig. 5a). When the covalent bond between $Z$ and $X$ was a non-aromatic double bond, the hybridisation of the amino nitrogen was characterised as $\mathrm{sp}^{2}$-like (the red bar in Fig. 5a). When the covalent bond was an aromatic double bond, the hybridisation of the amino nitrogen had two tendencies: $\mathrm{sp}^{2}$-like or $\mathrm{sp}^{3}$-like hybridisation (the yellow bar in Fig. 5a). In general, using the crystal structure database, the conformational distribution of a molecular fragment can be correlated with the potential energy surface calculated by ab initio methods [7c, 27]. Thus, the conformational energy surface as a function of the amino geometry of the dibenzylamino group and its analogues would have at least two potential wells, $\mathrm{sp}^{2}$-like and $\mathrm{sp}^{3}$-like hybridisations, when the target fragment was substituted by an aromatic ring. In addition, the relative locations of the phenyl rings on the target fragment were found to exhibit different patterns depending on the amino geometry (Fig. 5b). That is, the hybridisation of the amino nitrogen affects the overall molecular shapes. These results revealed that the conformational flexibility of the dibenzylamino group connected to an aromatic ring, such as in these pyrazine derivatives, was expected to favour the occurrence of conformational polymorphs.

[Fig. 5]

\subsection{Crystal structures of derivatives 1-5}

The results of the structural and statistical conformation analyses suggested that these derivatives have appropriate conformational potential surfaces for polymorphism. However, the derivatives did not all exhibit a polymorph based on each conformer (Group A-D), although the terminal substituents of the benzyl groups may have negligible effects on the stabilities of these conformations in the gas phase. The packing of the observed crystal structures was presumably affected by the substituents. We evaluated intermolecular interactions in all of the observed forms via crystal structure comparison, lattice energy calculation, and Hirshfeld surface analysis in order to estimate the effect of the terminal substituents on the packing of the crystal structures.

Table 3 shows the major intermolecular interactions which appeared as a short contact, which was defined as those that are shorter than the sum of the van der Waals radii. The observed short contacts were summarised in the supporting information (Table S5). In all of the obtained crystal structures, there were no strong and directional interactions such as a typical hydrogen bond. 
[Table 3]

One-dimensional chromophore stacking (1D column) was detected in all of the observed crystal structures (Fig. 6). Although there were differences in the chromophore stacking distances, which ranged from 3.098 (2R) to $8.962 \AA$ (3R) (Table 4), these differences were not correlated with the substituents on the benzyl groups. Molecular stacking in the 1D column was found to be dependent on the conformational similarity. The four forms in Group B, (2Y, 3Y, 4Y, and 50) had structural similarities in their 1D column structures. One of the two dibenzylamino groups of 10 , which was assigned to Group $\mathrm{C}$, had an amino group with $\mathrm{sp}^{3}$-like hybridisation, and the location of the phenyl rings was similar to those in Group B. The 1D column structure of this form was similar to those of the four forms in Group B. In contrast, the 1D column structures of $\mathbf{2 R}$ and $\mathbf{3 R}$ in Group A were quite distinct despite the conformational similarity. This was considered an indication that the terminal substituents of the benzyl groups, methyl groups in $\mathbf{2} \mathbf{R}$, and $\mathrm{Cl}$ atoms in $\mathbf{3} \mathbf{R}$ would play an important role in their crystal packing. In addition, the 1D column structure of $\mathbf{3 Y O}$ was different from those of the five forms in Groups B and C, although the amino nitrogen of 3YO, from Group D, also had $\mathrm{sp}^{3}$ like hybridisation. The molecular shape of $\mathbf{3 Y O}$ was different from those of the five forms because the location of the phenyl rings was different. The formation of their 1D columns would be directly dependent on the molecular shapes in these five forms.

\section{[Table 4]}

[Fig. 6]

The energy of the molecule $\cdots$ molecule interaction in the 1D column structures was calculated using the AA-CLP model. The molecular pair of the intra-1D column in each form was found to have the largest energy contribution in all of the molecular pairs of each form (Table 5), except for 3R. This result clearly indicated that the formation of the 1D column structure was important to the stability of the crystal structure in all of the observed forms other than $\mathbf{3 R}$.

Thermal observation revealed that the crystal forms of Groups B and C can be characterised as thermally stable forms of each derivative, because these forms did not transform into other forms until heated to their melting points. In contrast, the crystal forms in Groups A and D were regarded as thermally metastable forms, because these transformed into the corresponding crystal forms in Group 
B upon heating. DSC analysis supported this consideration. $\mathbf{2 R}$ and $\mathbf{3 R}$ in Group A transformed to $\mathbf{2 Y}$ and $3 \mathbf{Y}$ in Group B with an exothermic peak (Fig. S1b and c), respectively. According to Heat-ofTransition rule [28], if the phase transition between polymorphs is exothermic, in general, the polymorphs are monotropically related. Therefore, Group A was presumably characterised as a metastable form. Moreover, the calculated total crystal energy, defined as the summation of the relative conformational energy and the lattice energy, was higher in metastable forms $\mathbf{2 R}, \mathbf{3 Y O}$, and $\mathbf{3} \mathbf{R}$ than in the corresponding stable forms (Table S6). This calculated result also supported the above consideration. These results implied that the 1D column structures of the stable forms were slightly affected by the substituents, whereas the substituents on the benzyl groups had a large effect on the formation of the 1D columns of the metastable forms. The molecular arrangement in the $1 \mathrm{D}$ column was then interpreted in terms of intermolecular interactions.

[Table 5]

\subsection{Molecular arrangements in the $1 \mathrm{D}$ columns in the thermally stable forms}

The arrangements of the 1D columns of the stable forms 10, 2Y, 3Y, 4Y, and 50 were similar; $2 Y$, $\mathbf{3 Y}$, and $\mathbf{5 O}$ exhibited isomorphism. The arrangements of the 1D columns in $\mathbf{1 O}$ and $\mathbf{4 Y}$ were similar to those of the isomorphic group but with two slight differences, which were found in the packing of the phenyl rings and the inter-1D column interactions along the $c$-axis. In 10, two phenyl rings were packed between the adjacent 1D columns, forming two different packing motifs dependent on the structural nature of the bonded amino geometries. The benzyl groups bonded to an amino group with $\mathrm{sp}^{2}$-like hybridisation formed a herring-bone packing motif, and those bonded to an amino group with $\mathrm{sp}^{3}$-like hybridisation formed a face-to-face packing motif as displayed in Fig. 7. In the isomorphic group, all of the phenyl rings between the 1D columns were packed in the face-to-face motif. On the other hand, the herring-bone motif was observed only in the packing among the phenyl rings of the adjacent 1D columns in $\mathbf{4 Y}$. The contribution of the molecular pair containing these packing motifs was, however, found to have a small impact on their lattice energies (Table 5).

Intermolecular $\mathrm{C}-\mathrm{H} \cdots \pi$ interaction in $\mathbf{1 0}$ was observed along the $c$-axis, while the molecular pair along the $c$-axis was connected through $\mathrm{C}-\mathrm{H} \cdots \mathrm{N}$ interactions in all of the stable forms except for $\mathbf{1 0}$ (see Figs. 7-9). The difference between 10 and the isomorphic group was attributed to the size of the substituent at the 4-position of the benzyl group. The hydrogens in those positions in $\mathbf{1 0}$ formed short 
contacts with the hydrogen or carbon atom of a neighbouring molecule (Fig. 7a and Table S5). Introduction of the substituent at the 4-position of the benzyl group would generate a repulsive force between the 1D columns caused by the steric effect of the substituents on 10. The contribution of the molecular pair along the $c$-axis in $\mathbf{1 0}$ was larger than that of each molecular pair in the other stable forms (Table 5). Thus, the packing along the $c$-axis was probably affected by the difference in the conformation, rather than the difference in the packing motif of the phenyl rings.

Although isomorphism or isostructurality were observed in the stable forms, the differences in the conformations and the substituents caused a slight difference in the local packing.

[Fig. 7]

[Fig. 8]

[Fig. 9]

\subsection{D column arrangements of the thermally metastable forms}

The crystal structures of the metastable forms $\mathbf{2 R}, \mathbf{3 R}$, and $\mathbf{3 Y O}$ were different from those of the stable forms. In $\mathbf{2 R}$, the 1D chromophore stacking distance was shorter than that of $\mathbf{2 Y}$ (Table 4), and the calculation results for $\mathbf{2} \mathbf{R}$ showed that the contribution rate of the molecular pair in the intra-1D column to the lattice energy was larger than that of $\mathbf{2 Y}$ (Table 5). In contrast, the molecular pair along the $c$-axis received similar contributions in both $\mathbf{2 Y}$ and $\mathbf{2 R}$, although the distance between molecules along the $c$-axis in $\mathbf{2 R}(12.243 \AA$ ) was larger than that of $\mathbf{2 Y}$ (11.875 $\AA$ ) (Table 5). Intermolecular C$\mathrm{H} \cdots \mathrm{N}$ interaction along the $c$-axis was found in $\mathbf{2} \mathbf{R}$, as was observed in $\mathbf{2 Y}$. The $\mathrm{C}-\mathrm{H} \cdots \mathrm{N}$ interaction in $\mathbf{2} \mathbf{R}$ involved the terminal methyl group of the benzyl group, while that in $\mathbf{2 Y}$ was found between the hydrogen at the 3-position of the benzyl group and the cyano nitrogen (Table S5). Additionally, 2R formed several short contacts with respect to the terminal methyl group in the intra- and inter-1D column, while there was no short contact with respect to the terminal methyl groups in the crystal structure of $\mathbf{2 Y}$. This finding suggested that the terminal methyl group made a larger contribution to the stability of the metastable crystal structure than to the stable crystal structure.

Derivative $\mathbf{3}$ has three characterised polymorphs, although $\mathbf{3 Y O}$ might be a disappearing polymorph. The crystal structures of the metastable forms were quite distinct compared to that of $\mathbf{3 Y}$ (Fig. 9), although halogen interactions based on short contacts were observed in all three forms: $\mathrm{C}-\mathrm{H}{ }^{\cdots} \mathrm{Cl}$ interactions in $\mathbf{3 Y}$ and $\mathbf{3 R}$, and a C-Cl $\cdots \mathrm{N}$ interaction in $\mathbf{3 Y O}$ (represented by the red dashed line in 
Fig. 9). However, the interactions of the metastable forms would play a different role from that in $\mathbf{3 Y}$. The results of Hirshfeld surface analysis suggested that the halogen interactions in the crystal structures of $\mathbf{3 Y O}$ and $\mathbf{3 R}$ made larger contributions to their Hirshfeld surfaces than did that in $\mathbf{3 Y}$ (Fig. 10); the contributions of the $\mathrm{Cl} \cdots \mathrm{H}$ and $\mathrm{Cl} \cdots \mathrm{N}$ interactions were particularly large in the metastable forms. These halogen interactions, such as the $\mathrm{C}-\mathrm{H} \cdots \mathrm{Cl}$ and $\mathrm{C}-\mathrm{Cl} \cdots \mathrm{N}$ interactions, were known to be attractive forces which were attributed to the electrostatic, repulsion, and dispersion forces [29]. Thus, packing based on these attractive interactions was expected in the metastable forms. In $3 \mathbf{R}$, the largest energy contribution came from the molecular pair involved in the $\mathrm{C}-\mathrm{H} \cdots \pi$ interaction along the $b$-axis represented by the blue dotted line in Fig. 9, and the molecular pairs involved in the $\mathrm{C}-\mathrm{H} \cdots \mathrm{Cl}$ interactions made the second- and third-largest contributions. Although the molecular pair involved in the $\mathrm{C}-\mathrm{H} \cdots \mathrm{Cl}$ interaction also made the second-largest energy contribution in $\mathbf{3 Y}$, there was no more molecular pair involved in the $\mathrm{C}-\mathrm{H} \cdots \mathrm{Cl}$ interaction based on a short contact. The halogen interaction in $\mathbf{3 Y}$ presumably had a limited effect on the packing formation. In addition, Hirshfeld surface analysis revealed that the contribution of the $\mathrm{Cl} \cdots \mathrm{Cl}$ interaction in $\mathbf{3 Y}$ was the largest among the three forms. The distance of the shortest $\mathrm{Cl} \cdots \mathrm{Cl}$ interaction in $3 \mathbf{Y}$ was $3.624 \AA$, which was not shorter than the sum of van der Waals radii. The angles of C-Cl $\cdots \mathrm{Cl}-\mathrm{C}$ were both $132.1^{\circ}$, and this halogen interaction was classified as Type I geometry, which is regarded as space-filling type [30]. This feature confirmed that the crystal structure of $\mathbf{3 Y}$ was mainly identified by closed packing despite the existence of the halogen interaction. These results indicated that the weak interactions formed by the terminal substituents played an important role in the crystal packing of $\mathbf{3 R}$ rather than of $\mathbf{3 Y}$. In 3YO, the molecular pair involved in the $\mathrm{C}-\mathrm{N} \cdots \mathrm{Cl}$ interaction, which was a short contact, made a small energy contribution (0.94\%). However, the molecular pair that made the largest energy contribution included the $\mathrm{C}-\mathrm{H} \cdots \mathrm{Cl}$ interaction, although it was not a short contact $\left(3.144 \AA, 154.8^{\circ}\right)$. Although the halogen interaction in $\mathbf{3 Y O}$ made a smaller contribution than that of $\mathbf{3 R}$ did, the halogen atom of the terminal substituents probably played an important role in the crystal structures of both $\mathbf{3 Y O}$ and $\mathbf{3 R}$. These results suggested that, in this dye system, the occurrence of the metastable form would require weak interactions which were not observed in the closed packing of the stable form. The terminal substituents on the benzyl groups played a significant role in the formation of weak interactions which stabilised the crystal structures of the metastable forms in these derivatives.

[Fig. 10] 


\section{Conclusions}

In 2,5-diamino-3,6-dicyanopyrazine derivatives 1-5, the observed eight crystal structures were divided into four conformational groups regardless of the differences in the substituents. The major differences among the groups were attributed to the amino geometry. The analytical results based on the statistical search in the CSD suggested that the dibenzylamino groups had at least two potential wells on the potential surface with respect to the amino geometry when connected to an aromatic ring. In other words, the molecular flexibility of the dibenzylamino groups had a suitable potential surface for the occurrence of conformational polymorphism. However, having a suitable potential surface did not always lead to polymorphism in these pyrazine derivatives, that is, the polymorphs of the derivatives 2-4 were easily obtained using several solvents, whereas polymorphs in the derivatives $\mathbf{1}$ and 5 have not yet been obtained under many experimental conditions. Although it is possible that the derivatives $\mathbf{1}$ and $\mathbf{5}$ have polymorphs, the substituents affected the preference of occurrence of polymorphs in these derivatives. Crystal structure analysis revealed that the terminal substituents did not have a large impact on the closed packing in the stable forms, whereas the weak interactions related to the terminal substituents stabilised the packing of the metastable forms. In particular, the electrostatic property of a $\mathrm{Cl}$ atom was extremely important to the formation of the packing of the metastable forms in derivative 3 .

The molecular conformation and the effect of the substituents were essential factors for the occurrence of the conformational polymorphs in these derivatives.

\section{Acknowledgement}

The authors thank Dr. Mitsuhiro Yanagita of Nippon Soda Co. Ltd. for kindly providing dye samples. 


\section{References}

[1] J. Bernstein, Polymorphism in Molecular Crystals, Clarendon Press, Oxford, 2002.

[2] (a) Y. Eguchi and Y. Iitaka, Acta Cryst., 1974, B30, 2781-2783. (b) K. Szulzewsky, S. Kulpe, B. Schulz and H. Fichtner-Schmittler, Acta Pharm. Suec., 1982, 19, 457-470.

[3] A. J. Aguiar, J. Krc Jr., A. W. Kinkel and J. C. Samyn, J. Pharm. Sci., 1967, 56, 847-853.

[4] (a) L. Borka and J. K. Haleblian, Acta Pharm. Jugosl., 1990, 40, 71-94. (b) T. L. Threlfall, Analyst, 1995, 120, 2435-2459. (c) B. J. D. Le Révérend, P. J. Fryer, S. Coles and S. Bakalis, J. Am. Oil Chem. Soc., 2010, 87, 239-246. (d) H. Zollinger, Color Chemistry, 3rd Edition, Wiley-VCH, 2001. (e) T. Inabe and H. Tajima, Chem. Rev., 2004, 104, 5503-5533.

[5] (a) S. L. Price, Acta Cryst., 2013, B69, 313-328. (b) S. L. Price, Chem. Soc. Rev., 2014, 43, 20982111.

[6] L. Yu, S. M. Reutzel-Edens and C. A. Mitchell, Org. Process Res. Dev., 2000, 4, 396-402.

[7] (a) J. Bernstein and A. T. Hagler, J. Am. Chem. Soc., 1978, 100, 673-681. (b) A. Nangia, Acc. Chem. Res., 2008, 41, 595-604. (c) A. J. Cruz-Cabeza and J. Bernstein, Chem. Rev., 2014, 114, 2170-2191.

[8] (a) L. Yu, J. Phys. Chem., 2002, A106, 544-550. (b) L. Yu, Acc. Chem. Res., 2010, 43, 1257-1266. [9] For example, $N$-(p-dimethylaminobenzylidene)-p-nitroaniline (refcode MARZNA) with torsional flexibility was known to have four polymorphs, but all conformers among the polymorphs were the same, i.e. packing polymorphism. See H. Nakai, K. Ezumi and M. Shiro, Acta Cryst., 1981, B37, 193197.

[10] K. M. Lutker, Z. P. Tolstyka and A. J. Matzger, Cryst. Growth Des., 2008, 8, 136-139.

[11] V. López-Mejías, J. W. Kampf and A. J. Matzger, J. Am. Chem. Soc., 2012, 134, 9872-9875.

[12] O. G. Uzoh, A. J. Cruz-Cabeza and S. L. Price, Cryst. Growth Des., 2012, 12, 4230-4239.

[13] (a) S. K. Chandran, N. K. Nath, S. Roy and A. Nangia, Cryst. Growth Des., 2008, 8, 140-154. (b)

N. K. Nath and A. Nangia, Cryst. Growth Des., 2012, 12, 5411-5425.

[14] S. Matsumoto, Y. Uchida and M. Yanagita, Chem. Lett., 2006, 35, 654-655.

[15] (a) K. Shirai, A. Yanagisawa, H. Takahashi, K. Fukunishi and M. Matsuoka, Dyes Pigm., 1998, 39, 49-68. (b) J. H. Kim, S. R. Shin, M. Matsuoka and K. Fukunishi, Dyes Pigm., 1998, 39, 341-357.

[16] Rigaku, 1998, RAPID-AUTO. Rigaku Corporation, Tokyo, Japan.

[17] SHELXL97: G.M. Sheldrick, Acta Cryst., 2008, A64, 112-122.

[18] CrystalStructure 4.0: Crystal Structure Analysis Package, Rigaku Corporation, 2000-2010, Tokyo 196-8666, Japan.

[19] Mercury: C. F. Macrae, P. R. Edgington, P. McCabe, E. Pidcock, G. P. Shields, R. Taylor, M. Towler and J. van de Streek, J. Appl. Cryst., 2006, 39, 453-457.

[20] J. D. Dunitz and J. Bernstein, Acc. Chem. Res., 1995, 28, 193-200.

[21] Gaussian 09, Revision B.01, M. J. Frisch, G. W. Trucks, H. B. Schlegel, G. E. Scuseria, M. A. Robb, J. R. Cheeseman, G. Scalmani, V. Barone, B. Mennucci, G. A. Petersson, H. Nakatsuji, M. 
Caricato, X. Li, H. P. Hratchian, A. F. Izmaylov, J. Bloino, G. Zheng, J. L. Sonnenberg, M. Hada, M. Ehara, K. Toyota, R. Fukuda, J. Hasegawa, M. Ishida, T. Nakajima, Y. Honda, O. Kitao, H. Nakai, T. Vreven, J. A. Montgomery, Jr., J. E. Peralta, F. Ogliaro, M. Bearpark, J. J. Heyd, E. Brothers, K. N. Kudin, V. N. Staroverov, T. Keith, R. Kobayashi, J. Normand, K. Raghavachari, A. Rendell, J. C. Burant, S. S. Iyengar, J. Tomasi, M. Cossi, N. Rega, J. M. Millam, M. Klene, J. E. Knox, J. B. Cross, V. Bakken, C. Adamo, J. Jaramillo, R. Gomperts, R. E. Stratmann, O. Yazyev, A. J. Austin, R. Cammi, C. Pomelli, J. W. Ochterski, R. L. Martin, K. Morokuma, V. G. Zakrzewski, G. A. Voth, P. Salvador, J. J. Dannenberg, S. Dapprich, A. D. Daniels, O. Farkas, J. B. Foresman, J. V. Ortiz, J. Cioslowski and D. J. Fox, Gaussian, Inc., Wallingford CT, 2010.

[22] J. D. Chai and M. Head-Gordon, Phys. Chem. Chem. Phys., 2008, 10, 6615-6620.

[23] A.Gavezzotti, New J. Chem., 2011, 35, 1360-1368.

[24] J. J. McKinnon, M. A. Spackman and A. S. Mitchell, Acta Cryst., 2004, B60, 627-668.

[25] ConQuest: I. J. Bruno, J. C. Cole, P. R. Edgington, M. Kessler, C. F. Macrae, P. McCabe, J. Pearson and R. Taylor, Acta Cryst., 2002, B58, 389-397.

[26] M. Lang, A. L. Grzesiak and A. J. Matzger, J. Am. Chem. Soc., 2002, 124, 14834-14835.

[27] K. A. Brameld, B. Kuhn, D. C. Reuter and M. Stahl, J. Chem. Inf. Model., 2008, 48, 1-24.

[28] A. Burger, R. Ramberger, Mikrochim. Acta, 1979, 2, 259-271.

[29] (a) G. R. Desiraju and R. Parthasarathy, J. Am. Chem. Soc., 1989, 111, 8725-8726. (b) S. L. Price, A. J. Stone, J. Lucas, R. S. Rowland and A. E. Thornley, J. Am. Chem. Soc., 1994, 116, 4910-4918. (c) J. P. M. Lommerse, A. J. Stone, R. Taylor and F. H. Allen, J. Am. Chem. Soc., 1996, 118, 31083116.

[30] C. M. Reddy, M. T. Kirchner, R. C. Gundakaram, K. A. Padmanabhan and G. R. Desiraju, Chem. Eur. J., 2006, 12, 2222-2234. 
Figure legends

Figure 1. A series of 2,5-bis( $N, N$-dibenzylamino)-3,6-dicyanopyrazine derivatives.

Figure 2. Colour-polymorphism in the pyrazine derivatives.

Figure 3. Target fragment for the compound search in the CSD. $Z$ represents any atom except for hydrogen. $X$ represents any atom including hydrogen. The dashed line represents any covalent bond such as a single bond, non-aromatic double bond, aromatic double bond, or triple bond. No compound featured a $Z-X$ triple bond. The compounds identified in the search were divided into three groups depending on the type of covalent bond between $Z$ and $X$.

Figure 4. ORTEP diagrams of the crystal forms of derivatives 1-5.

Figure 5. Geometrical distribution of the compounds containing the target fragment in the CSD according to (a) the pyramid cone angle $(a+b+c)$ and (b) the torsional angle around the amino nitrogen ( $a-b-c-d$ and $a-b-c^{\prime}-d^{\prime}$ ). Point $b$ of the torsional angle was the centre of the least squares plane defined by the three carbons on the amino group. In (a), the blue bar represents the distribution of the compounds with a $Z-X$ single bond in the target fragment, the red bar represents the compounds with a $Z-X$ non-aromatic double bond in the target fragment, and the yellow bar represents the compounds with an aromatic double bond. In (b), the histogram depended on the hybridisation of the amino nitrogen in the target fragment. An amino geometry with a pyramid cone angle larger than $348^{\circ}$ was characterised as having $\mathrm{sp}^{2}$-like hybridisation. The fragments in both figures were part of the target fragment. $Z$ represents any non-hydrogen atom.

Figure 6. Major 1D column structures of all observed crystal structures. The structures of $\mathbf{2 Y}$ and $\mathbf{4 Y}$ were the same as that of $\mathbf{3 Y}$. The short contacts represented by the blue lines were observed in the column structures of $\mathbf{1 O}, \mathbf{2 R}$, and $\mathbf{3 Y O}$.

Figure 7. 1D column arrangement of 10. (a) The $\mathrm{C}-\mathrm{H} \cdots \pi / \mathrm{C}$ interactions in the inter-1D column are represented by the blue dashed lines. The red dashed lines represent the short contacts at the hydrogen atom in the 4-position of the benzyl group. (b) The benzyl groups formed two packing motifs: the herring-bone packing and the face-to-face packing. The herring-bone packing is indicated by the green square and the face-to-face packing is indicated by the orange square in (a).

Figure 8. 1D column arrangements of $\mathbf{2 Y}$ and $\mathbf{2}$. The $\mathrm{C}-\mathrm{H} \cdots \mathrm{N}$ interactions along the $c$-axis are represented by the red dashed lines. The benzyl groups of $\mathbf{2 Y}$ formed the face-to-face packing 
represented by the orange squares. The benzyl group packing of $\mathbf{2} \mathbf{R}$ was different from that of $\mathbf{2 Y}$.

Figure 9. 1D column arrangements of three polymorphs of 3 . The halogen interactions in the inter-1D column are represented by the red dashed lines. The C-H $\cdots \pi$ interactions in the inter-1D column are represented by the blue dashed lines. All forms adopted the face-to-face packing indicated by the orange squares.

Figure 10. Relative contribution to the Hirshfeld surface area of derivative 3. X1 represents nitrogen, carbon, or hydrogen atoms. X2 represents carbon or hydrogen atoms. 
Table legends

Table 1. Crystallographic information on the analysed forms of derivatives 1-5.

Table 2. Significant molecular geometries.

Table 3. Major intermolecular interactions in terms of short contacts.

Table 4. Chromophore distances in the 1D columns.

Table 5. Total energy of all molecular pairs and the contributions of the major molecular pairs. 
Figure 1. A series of 2,5-bis( $N, N$-dibenzylamino)-3,6-dicyanopyrazine derivatives.<smiles>[R20]c1nc(C#N)c([Y20])nc1C#N</smiles><smiles>[Y]C=[V]</smiles><smiles></smiles><smiles>[R]CCc1ccc(Cl)cc1</smiles><smiles></smiles><smiles>CC=C(C)C=C(C)CC=[Sb]</smiles>

6: $\mathrm{R}=-\mathrm{H}_{2} \mathrm{C}$<smiles>C=C(Cl)CCC</smiles><smiles>[Y]=CCc1ccccc1Br</smiles> 
Figure 2. Colour-polymorphism in the pyrazine derivatives.

1

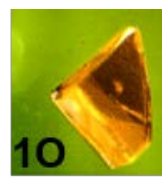

2

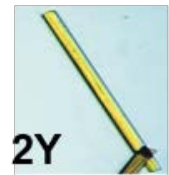

3

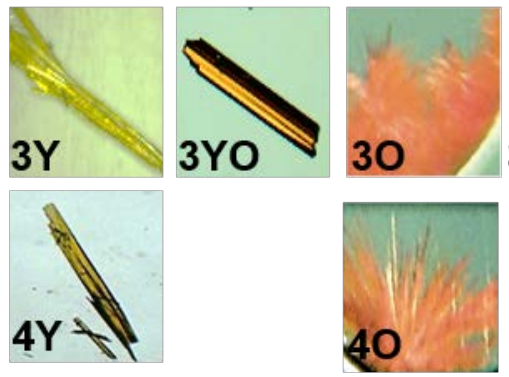

5

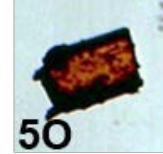


Figure 3. Target fragment for the compound search in the CSD. $Z$ represents any atom except for hydrogen. $X$ represents any atom including hydrogen. The dashed line represents any covalent bond such as a single bond, non-aromatic double bond, aromatic double bond, or triple bond. No compound featured a $Z-X$ triple bond. The compounds identified in the search were divided into three groups depending on the type of covalent bond between $Z$ and $X$.

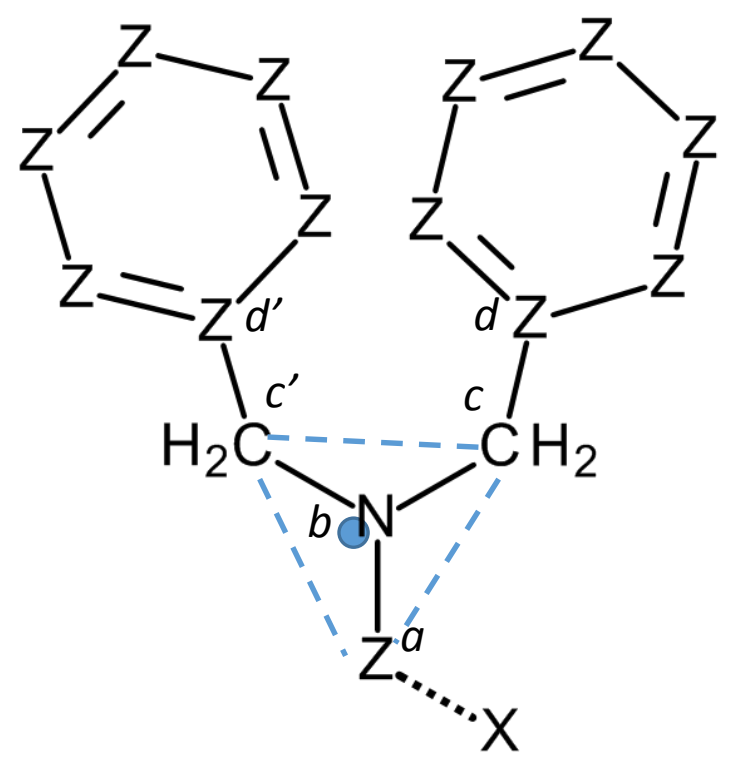


Figure 4. ORTEP diagrams of the crystal forms of derivatives 1-5.

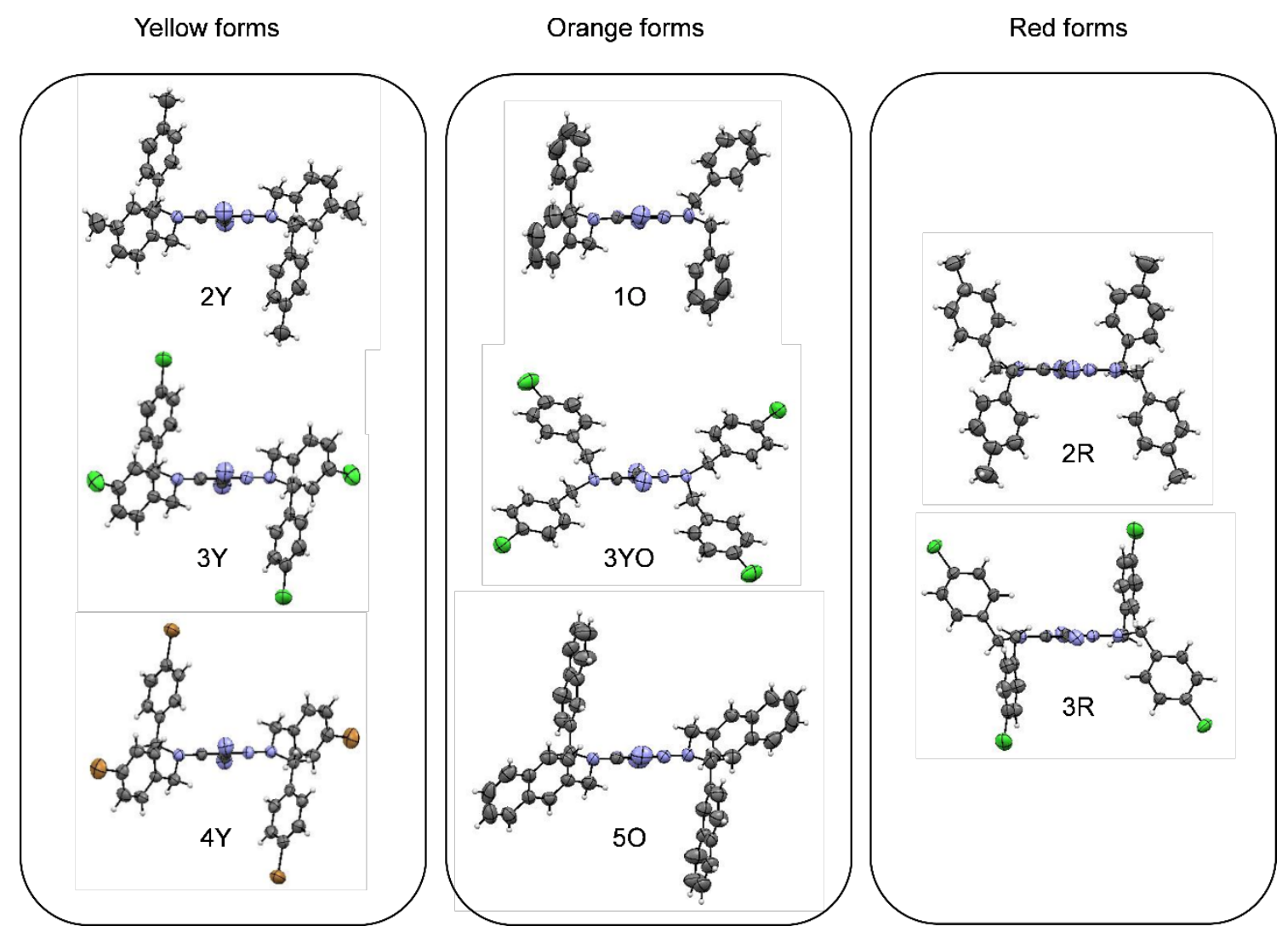


Figure 5. Geometrical distribution of the compounds containing the target fragment in the CSD according to (a) the pyramid cone angle $(a+b+c)$ and (b) the torsional angle around the amino nitrogen ( $a-b-c-d$ and $a-b-c^{\prime}-d^{\prime}$ ). Point $b$ of the torsional angle was the centre of the least squares plane defined by the three carbons on the amino group. In (a), the blue bar represents the distribution of the compounds with a $Z-X$ single bond in the target fragment, the red bar represents the compounds with a $Z$ - $X$ non-aromatic double bond in the target fragment, and the yellow bar represents the compounds with an aromatic double bond. In (b), the histogram depended on the hybridisation of the amino nitrogen in the target fragment. An amino geometry with a pyramid cone angle larger than $348^{\circ}$ was characterised as having $\mathrm{sp}^{2}$-like hybridisation. The fragments in both figures were part of the target fragment. $Z$ represents any non-hydrogen atom.

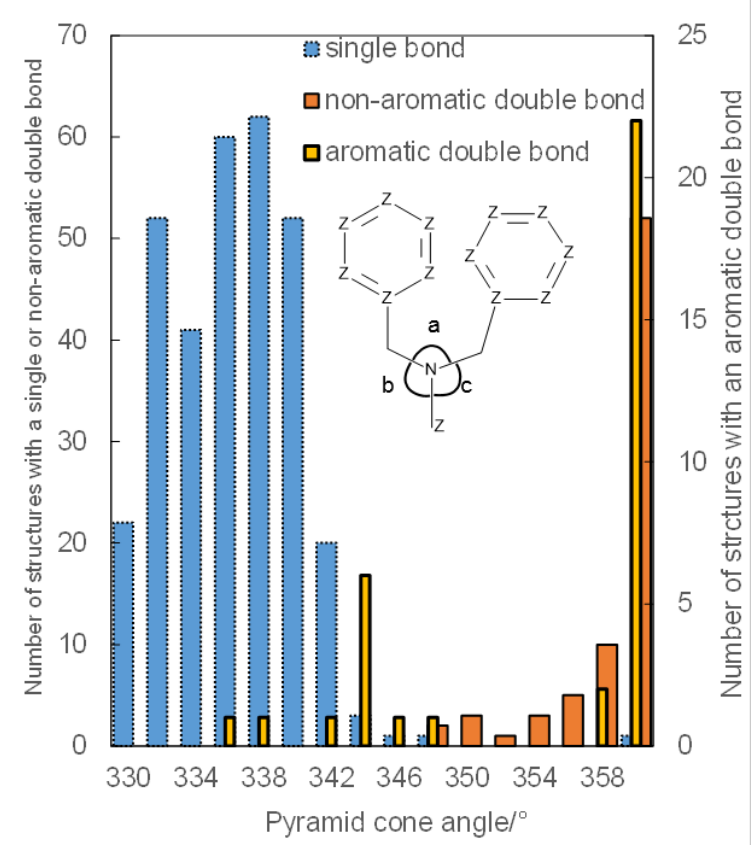

(a) Amino geometry

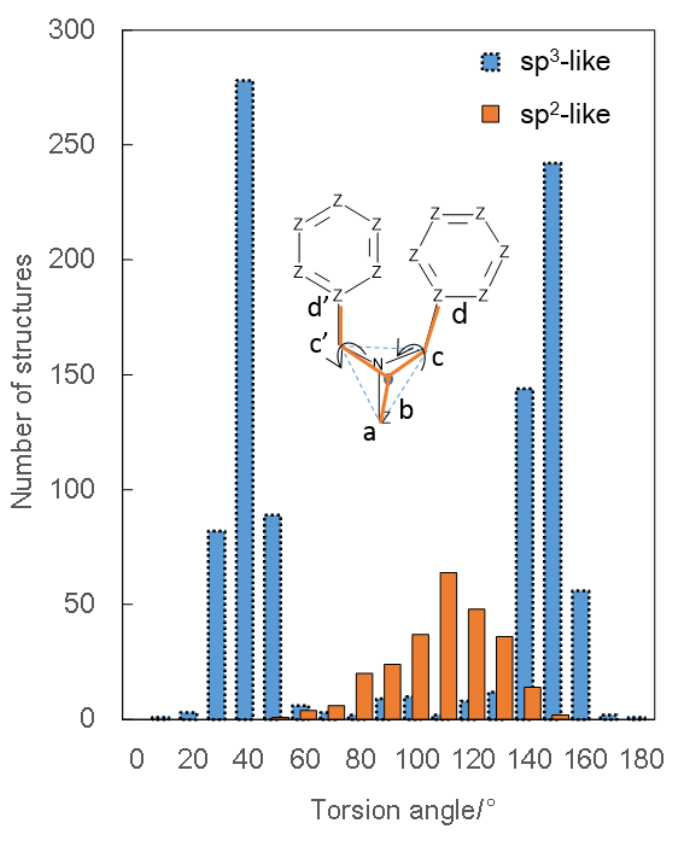

(b) Phenyl location 
Figure 6. Major 1D column structures of all observed crystal structures. The structures of $\mathbf{2 Y}$ and $\mathbf{4 Y}$ were the same as that of $\mathbf{3 Y}$. The short contacts represented by the blue lines were observed in the column structures of $\mathbf{1 0}, \mathbf{2 R}$, and $3 \mathbf{Y O}$.
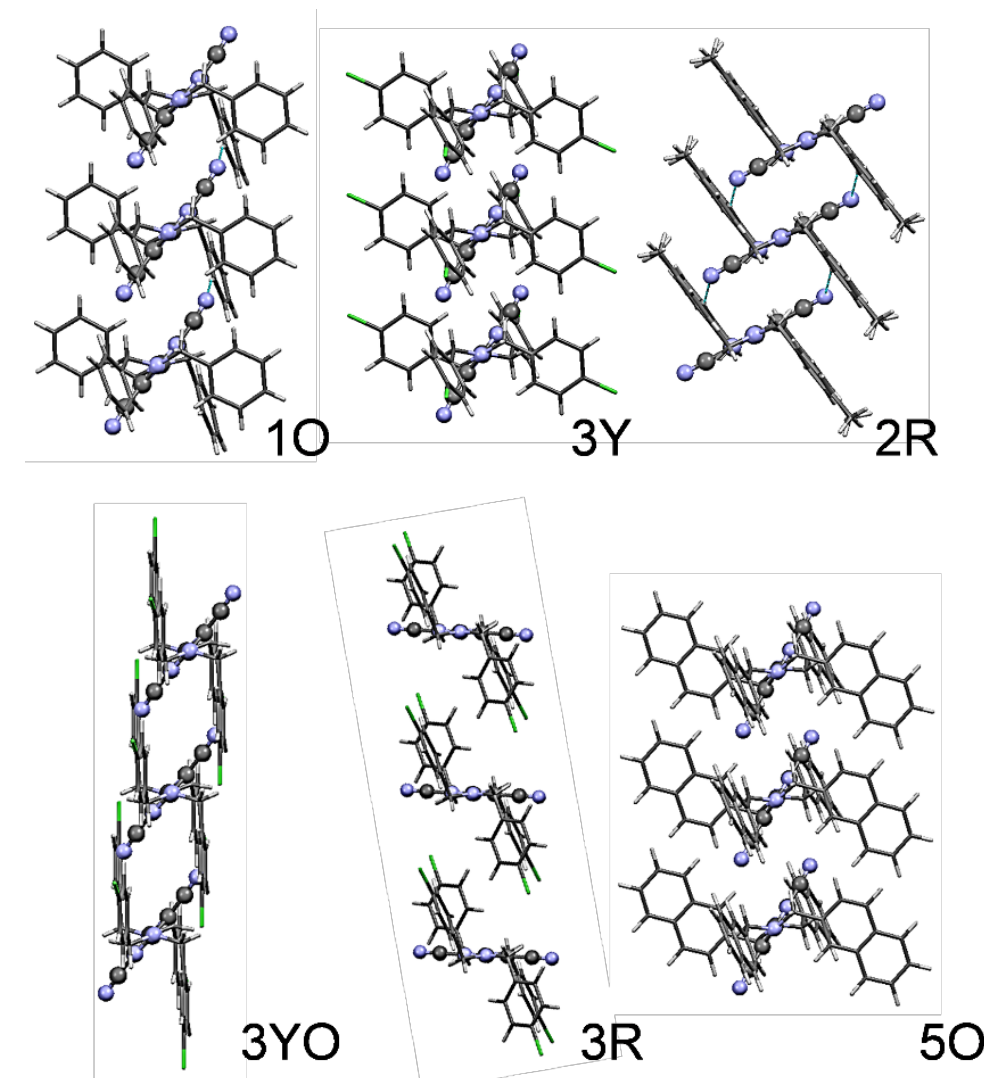
Figure 7. 1D column arrangement of 10 . (a) The $\mathrm{C}-\mathrm{H} \cdots \pi / \mathrm{C}$ interactions in the inter-1D column are represented by the blue dashed lines. The red dashed lines represent the short contacts at the hydrogen atom in the 4-position of the benzyl group. (b) The benzyl groups formed two packing motifs: the herring-bone packing and the face-to-face packing. The herring-bone packing is indicated by the green square and the face-to-face packing is indicated by the orange square in (a).

(a) The column arrangement
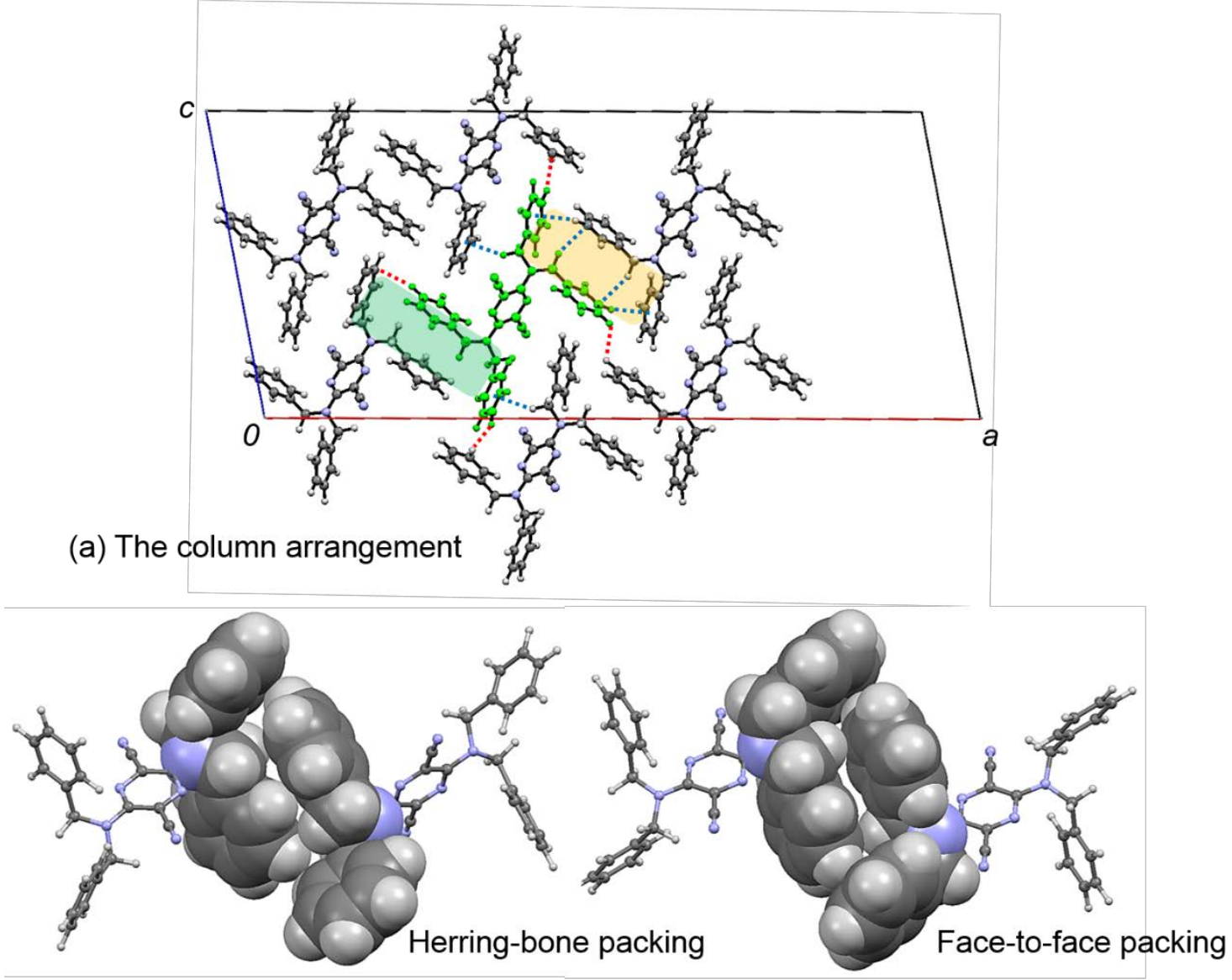

(b) The benzyl group packing 
Figure 8. 1D column arrangements of $\mathbf{2 Y}$ and $\mathbf{2}$. The $\mathrm{C}-\mathrm{H} \cdots \mathrm{N}$ interactions along the $c$-axis are represented by the red dashed lines. The benzyl groups of $\mathbf{2} \mathbf{Y}$ formed the face-to-face packing represented by the orange squares. The benzyl group packing of $\mathbf{2} \mathbf{R}$ was different from that of $\mathbf{2 Y}$.
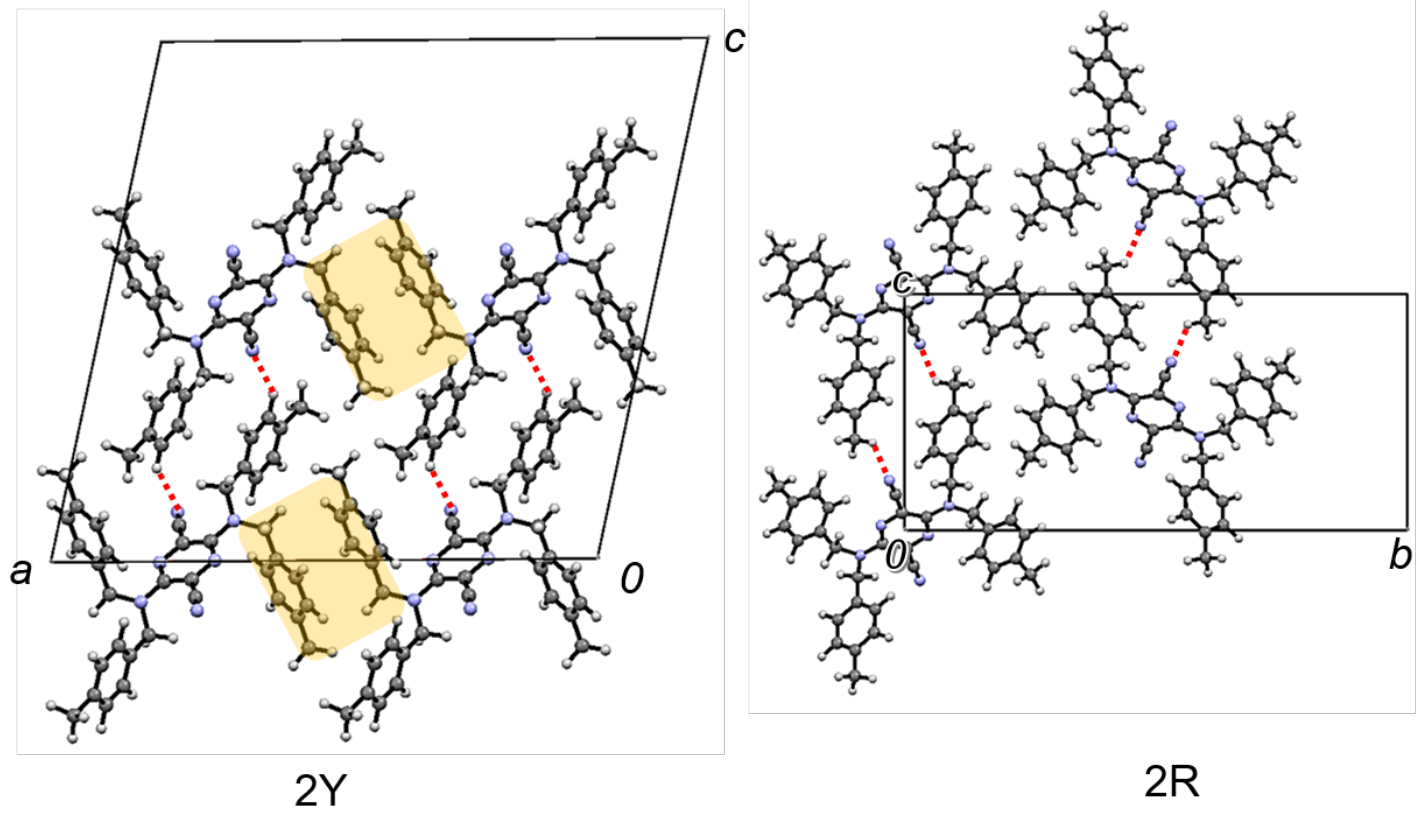
Figure 9. 1D column arrangements of three polymorphs of 3 . The halogen interactions in the inter-1D column are represented by the red dashed lines. The $\mathrm{C}-\mathrm{H} \cdots \pi$ interactions in the inter-1D column are represented by the blue dashed lines. All forms adopted the face-to-face packing indicated by the orange squares.

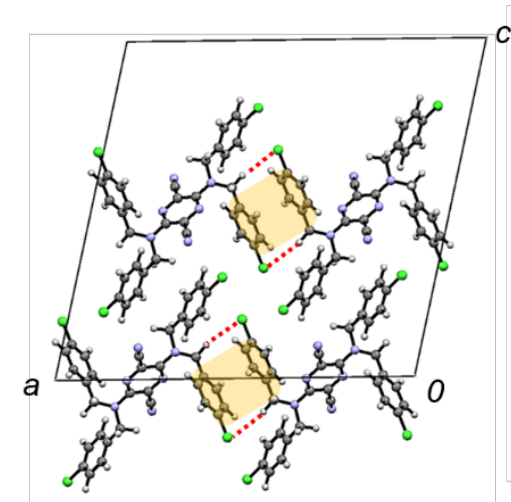

$3 Y$

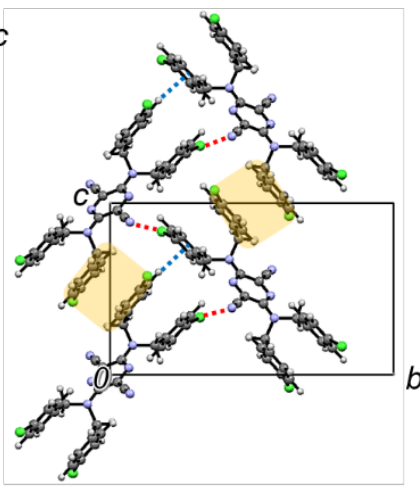

$3 Y O$

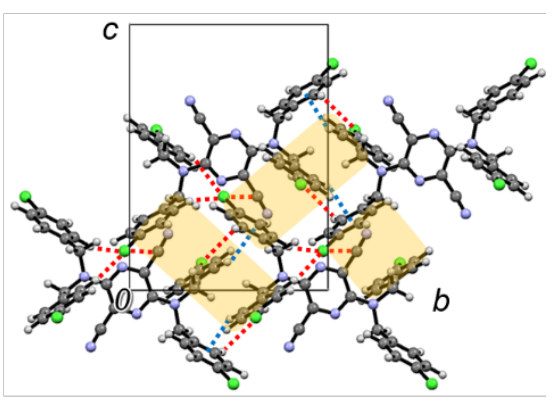

$3 R$ 
Figure 10. Relative contribution to the Hirshfeld surface area of derivative 3. X1 represents nitrogen, carbon, or hydrogen atoms. X2 represents carbon or hydrogen atoms.

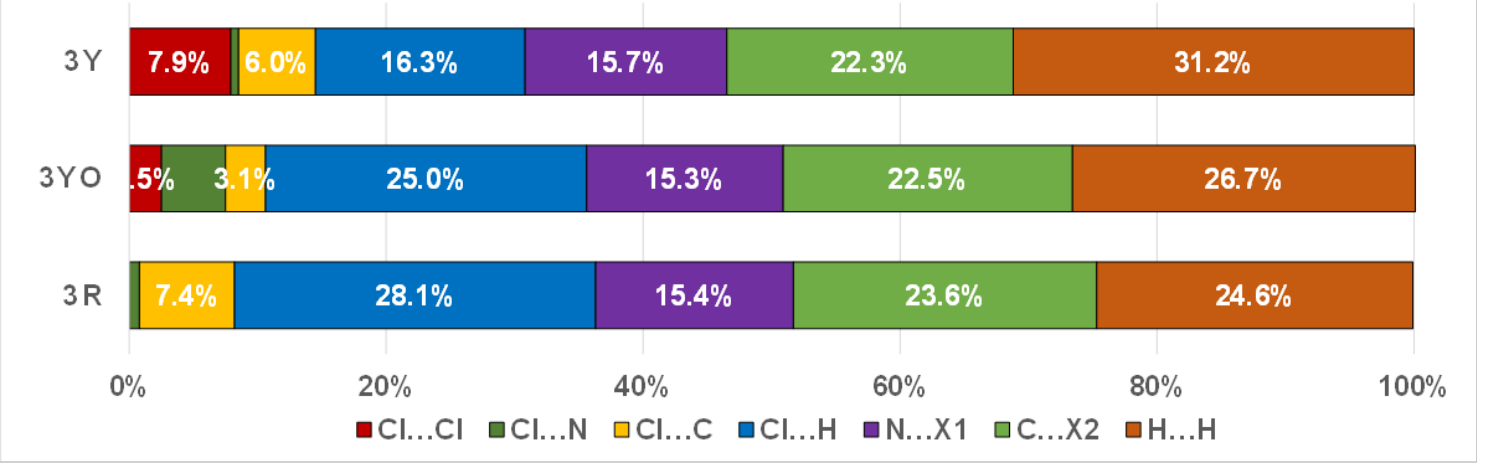


Table 1. Crystallographic information on the analysed forms of derivatives 1-5.

\begin{tabular}{|c|c|c|c|c|c|c|c|c|}
\hline Crystal forms & 10 & $2 Y$ & 2R & $3 \mathbf{Y}^{r e f 14}$ & $3 Y O$ & $3 \mathbf{R}^{r e f 14}$ & $\mathbf{4} \mathbf{Y}^{r e f 14}$ & 50 \\
\hline Formula & $\mathrm{C}_{34} \mathrm{H}_{28} \mathrm{~N}_{6}$ & $\mathrm{C}_{38} \mathrm{H}_{36} \mathrm{~N}_{6}$ & $\mathrm{C}_{38} \mathrm{H}_{36} \mathrm{~N}_{6}$ & $\begin{array}{l}\mathrm{C}_{34} \mathrm{H}_{24} \mathrm{~N}_{6} \\
\mathrm{Cl}_{4}\end{array}$ & $\begin{array}{l}\mathrm{C}_{34} \mathrm{H}_{24} \mathrm{~N}_{6} \\
\mathrm{Cl}_{4}\end{array}$ & $\begin{array}{l}\mathrm{C}_{34} \mathrm{H}_{24} \mathrm{~N}_{6} \\
\mathrm{Cl}_{4}\end{array}$ & $\begin{array}{l}\mathrm{C}_{34} \mathrm{H}_{24} \mathrm{~N}_{6} \\
\mathrm{Br}_{4}\end{array}$ & $\mathrm{C}_{50} \mathrm{H}_{36} \mathrm{~N}_{6}$ \\
\hline $\begin{array}{l}\text { Formula } \\
\text { weight }\end{array}$ & 520.64 & 576.74 & 576.74 & 658.42 & 658.42 & 658.42 & 836.22 & 720.87 \\
\hline Space group & $C 2 / c$ & $C 2 / c$ & $P 2_{1} / c$ & $C 2 / c$ & $P 2{ }_{1} / n$ & $P 2_{1} / n$ & $P 2_{1} / n$ & $C 2 / c$ \\
\hline$T(\mathrm{~K})$ & 296 & 296 & 296 & 296 & 296 & 296 & 296 & 296 \\
\hline$a(\AA)$ & $\begin{array}{l}46.128(1 \\
2)\end{array}$ & $23.613(5)$ & $4.832(8)$ & $23.485(5)$ & $7.680(2)$ & $9.441(2)$ & $14.589(6)$ & 23.947(7) \\
\hline$b(\AA)$ & $\begin{array}{l}6.2135(1 \\
4)\end{array}$ & $\begin{array}{l}5.9425(1 \\
0)\end{array}$ & $26.06(4)$ & $5.974(1)$ & $18.549(4)$ & $11.084(2)$ & $5.892(3)$ & $\begin{array}{l}\text { 6.9011(1 } \\
3)\end{array}$ \\
\hline$c(\AA)$ & $20.163(5)$ & $22.998(5)$ & $\begin{array}{l}12.243(1 \\
5)\end{array}$ & $22.593(7)$ & $11.229(3)$ & 15.303(3) & $18.492(5)$ & $23.640(8)$ \\
\hline$\alpha\left(^{\circ}\right)$ & 90 & 90 & 90 & 90 & 90 & 90 & 90 & 90 \\
\hline$\beta\left(^{\circ}\right)$ & $\begin{array}{l}100.884( \\
19)\end{array}$ & $\begin{array}{l}\text { 102.411( } \\
8)\end{array}$ & $91.40(8)$ & 102.69(1) & $92.71(2)$ & $\begin{array}{l}104.380( \\
9)\end{array}$ & $92.52(3)$ & $\begin{array}{l}104.564( \\
11)\end{array}$ \\
\hline$\gamma\left({ }^{\circ}\right)$ & 90 & 90 & 90 & 90 & 90 & 90 & 90 & 90 \\
\hline$Z$ & 8 & 4 & 2 & 4 & 2 & 2 & 2 & 4 \\
\hline$V\left(\AA^{3}\right)$ & $5675(3)$ & $\begin{array}{l}3151.6(1 \\
1)\end{array}$ & 1541(4) & 3092.3(1) & 1597.9(6) & 1551.1(5) & $\begin{array}{l}\text { 1588.1(1 } \\
0)\end{array}$ & $\begin{array}{l}3781.3(1 \\
7)\end{array}$ \\
\hline$D_{\text {calc }}\left(\mathrm{g} / \mathrm{cm}^{3}\right)$ & 1.219 & 1.215 & 1.243 & 1.414 & 1.368 & 1.410 & 1.749 & 1.266 \\
\hline$F(000)$ & 2192 & 1224 & 612 & 1352 & 676 & 676 & 820 & 1512 \\
\hline$\mu\left(\mathrm{mm}^{-1}\right)$ & 0.580 & 0.569 & 0.581 & 3.760 & 3.639 & 3.748 & 6.466 & 0.588 \\
\hline $\begin{array}{l}\text { No. of reflns } \\
\text { collection }\end{array}$ & 18545 & 12678 & 6429 & 13712 & 10621 & 14137 & 12979 & 15957 \\
\hline $\begin{array}{l}\text { No. of unique } \\
\text { reflns } \\
\text { /parameters }\end{array}$ & $4794 / 361$ & 2829/199 & 2763/199 & $2618 / 211$ & 2712/199 & $2818 / 211$ & $2671 / 212$ & $3392 / 258$ \\
\hline$R_{1} / \mathrm{w} R_{2}$ & $\begin{array}{l}0.0744 / 0 . \\
1771\end{array}$ & $\begin{array}{l}0.0497 / 0 . \\
1392\end{array}$ & $\begin{array}{l}0.0754 / 0 . \\
2182\end{array}$ & $\begin{array}{l}0.0470 / 0 \\
0620\end{array}$ & $\begin{array}{l}0.0650 / 0 \\
1694\end{array}$ & $\begin{array}{l}0.0470 / 0 . \\
1190\end{array}$ & $\begin{array}{l}0.0510 / 0 . \\
1390\end{array}$ & $\begin{array}{l}0.0619 / 0 . \\
1712\end{array}$ \\
\hline GOF & 0.932 & 1.052 & 1.005 & 1.279 & 1.089 & 1.062 & 1.376 & 1.015 \\
\hline
\end{tabular}


Table 2. Significant molecular geometries.

\begin{tabular}{|c|c|c|c|c|c|c|}
\hline & \multirow{2}{*}{$\begin{array}{c}\text { Bond } \\
\text { length/Å }\end{array}$} & \multirow{2}{*}{$\begin{array}{l}\begin{array}{c}\text { Calculated } \\
\text { angle }^{a}{ }^{\circ}\end{array} \\
\text { Pyramid } \\
\text { cone angle }\end{array}$} & \multicolumn{4}{|c|}{ Torsion angle $/^{\circ}$} \\
\hline & & & $\begin{array}{l}\text { N1-C1- } \\
\text { N3-C4 }\end{array}$ & $\begin{array}{l}\text { N1-C1- } \\
\text { N3-C5 }\end{array}$ & $\begin{array}{l}\mathrm{C} 1-\mathrm{cg}^{c}- \\
\mathrm{C} 4-\mathrm{C} 6\end{array}$ & $\begin{array}{l}\mathrm{C} 1-\mathrm{cg}^{\mathrm{c}}- \\
\mathrm{C} 5-\mathrm{C} 12\end{array}$ \\
\hline \multirow[t]{2}{*}{$10^{d}$} & $1.368(3)$ & 358.3 & $19.9(3)$ & $144.7(2)$ & 57.6 & 122.1 \\
\hline & 1.393(3) & 342.8 & 17.1(3) & $116.4(2)$ & 37.5 & 138.0 \\
\hline $2 \mathbf{Y}$ & $1.392(2)$ & 345.0 & $20.7(2)$ & $116.0(2)$ & 34.7 & 138.9 \\
\hline $2 \mathbf{R}$ & $1.362(6)$ & 360.0 & $2.5(6)$ & $174.7(4)$ & 98.6 & 104.1 \\
\hline $3 \mathbf{Y}$ & $1.397(3)$ & 345.8 & 20.6(3) & $117.2(2)$ & 35.9 & 140.4 \\
\hline $3 Y O$ & $1.384(3)$ & 348.0 & 25.7(3) & $114.8(2)$ & 104.7 & 133.8 \\
\hline $3 \mathbf{R}$ & $1.366(3)$ & 359.5 & $9.5(3)$ & $179.5(2)$ & 95.5 & 101.9 \\
\hline $4 Y$ & 1.391(7) & 344.3 & 24.6(7) & 111.5(5) & 33.9 & 139.6 \\
\hline 50 & $1.398(4)$ & 341.1 & $14.6(4)$ & 116.7(3) & 33.5 & 143.3 \\
\hline
\end{tabular}

${ }^{a}$ All angles were calculated using Mercury 3.3.

${ }^{b}$ The pyramid cone angle was the summation of the three angles around the amino nitrogen (see Fig. 5a).

${ }^{c} c g$ represents the centre of the least squares plane created by the three carbon atoms of the amino group (see Fig. 5b).

${ }^{d}$ The crystal structure of derivative $\mathbf{1}$ has one molecule in the asymmetric unit; hence, there are two values for $\mathbf{1}$. The other forms have a half molecule in the asymmetric unit. 
Table 3. Major intermolecular interactions in terms of short contacts ${ }^{a}$.

\begin{tabular}{|c|c|c|}
\hline & $\begin{array}{l}\text { Intra-1D } \\
\text { column }\end{array}$ & Inter-1D column \\
\hline 10 & $\mathrm{C}-\mathrm{H}_{\mathrm{ph}} \cdots \mathrm{N}_{\mathrm{CN}}$ & $\mathrm{C}-\mathrm{H}_{\mathrm{CH} 2} \cdots \pi_{\mathrm{ph}}, \mathrm{C}-\mathrm{H}_{\mathrm{ph}} \cdots \mathrm{C}_{\mathrm{ph}} / \pi_{\mathrm{ph}}, \mathrm{C}-\mathrm{H}_{\mathrm{CH} 2} \cdots \mathrm{C}_{\mathrm{ph}}$ \\
\hline $2 \mathbf{Y}$ & N.A. & $\mathrm{C}-\mathrm{H}_{\mathrm{ph}} \cdots \mathrm{N}_{\mathrm{CN}}$ \\
\hline $2 \mathbf{R}$ & $\begin{array}{l}\mathrm{C}-\mathrm{H}_{\mathrm{ph}} \cdots \mathrm{N}_{\mathrm{CN}} \\
\mathrm{C}-\mathrm{H}_{\mathrm{Me}} \cdots \mathrm{C}_{\mathrm{ph}}\end{array}$ & $\mathrm{C}-\mathrm{H}_{\mathrm{Me}} \cdots \mathrm{N}_{\mathrm{CN}}, \mathrm{C}-\mathrm{H}_{\mathrm{Me}} \cdots \mathrm{C}_{\mathrm{ph}}$ \\
\hline $3 \mathbf{Y}$ & N.A. & $\mathrm{C}-\mathrm{H}_{\mathrm{ph}} \cdots \mathrm{N}_{\mathrm{CN}}, \mathrm{C}-\mathrm{H}_{\mathrm{CH} 2} \cdots \mathrm{Cl}$ \\
\hline $3 Y O$ & $\mathrm{C}-\mathrm{H}_{\mathrm{ph}} \cdots \mathrm{N}_{\mathrm{CN}}$ & $\mathrm{C}-\mathrm{Cl} \cdots \mathrm{N}_{\mathrm{CN}}, \mathrm{C}-\mathrm{H}_{\mathrm{ph}} \cdots \mathrm{N}_{\mathrm{py}}, \mathrm{C}-\mathrm{H}_{\mathrm{ph}} \cdots \pi_{\mathrm{ph}}, \mathrm{C}-\mathrm{H}_{\mathrm{ph}} \cdots \mathrm{C}_{\mathrm{py}}, \mathrm{C}-\mathrm{H}_{\mathrm{ph}} \cdots \mathrm{C}_{\mathrm{CN}}$ \\
\hline $3 \mathbf{R}$ & N.A. & $\mathrm{C}-\mathrm{H}_{\mathrm{ph}} \cdots \mathrm{Cl}, \mathrm{C}-\mathrm{H}_{\mathrm{ph}} \cdots \mathrm{N}_{\mathrm{CN}}, \mathrm{C}_{\mathrm{CN}} \cdots \mathrm{Cl}, \mathrm{C}-\mathrm{H}_{\mathrm{ph}} \cdots \pi_{\mathrm{ph}}$ \\
\hline $4 \mathbf{Y}$ & N.A. & $\mathrm{C}-\mathrm{H}_{\mathrm{ph}} \cdots \mathrm{N}_{\mathrm{CN}}, \mathrm{C}-\mathrm{H}_{\mathrm{ph}} \cdots \mathrm{C}_{\mathrm{ph}}, \mathrm{C}-\mathrm{H}_{\mathrm{ph}} \cdots \mathrm{Br}, \mathrm{C}-\mathrm{H}_{\mathrm{CH} 2} \cdots \mathrm{Br}$ \\
\hline 50 & $\mathrm{C}-\mathrm{N}_{\mathrm{CN}} \cdots \mathrm{C}_{\mathrm{CN}}$ & $\mathrm{C}-\mathrm{H}_{\mathrm{ph}} \cdots \mathrm{N}_{\mathrm{CN}}, \mathrm{C}-\mathrm{H}_{\mathrm{CH} 2} \cdots \mathrm{C}_{\mathrm{ph}}, \mathrm{C}-\mathrm{H}_{\mathrm{ph}} \cdots \mathrm{C}_{\mathrm{ph}}$ \\
\hline
\end{tabular}


Table 4. Chromophore distances in the 1D columns.

\begin{tabular}{lccc}
\hline & & $\begin{array}{c}\text { Distance between } \\
\text { the chromophore } \\
\text { planes }{ }^{b} / \AA\end{array}$ & Symmetry operation \\
\hline $\mathbf{1 0}$ & 6.214 & 3.439 & $x, \pm 1+y, z$ \\
$\mathbf{2 Y}$ & 5.943 & 3.356 & $x, \pm 1+y, z$ \\
$\mathbf{2 R}$ & 4.832 & 3.098 & $\pm 1+x, y, z$ \\
$\mathbf{3 Y}$ & 5.974 & 3.372 & $x, \pm 1+y, z$ \\
$\mathbf{3 Y O}$ & 7.680 & 5.699 & $\pm 1+x, y, z$ \\
$\mathbf{3 R}$ & 9.441 & 8.962 & $\pm 1+x, y, z$ \\
$\mathbf{4 Y}$ & 5.892 & 3.422 & $x, \pm 1+y, z$ \\
$\mathbf{5 O}$ & 6.901 & 3.230 & $x, \pm 1+y, z$ \\
\hline
\end{tabular}

${ }^{a}$ Distance between the centres of pyrazine rings in the 1D column.

${ }^{b}$ Distance between the least squares plane of two pyrazine rings in the 1D column. 
Table 5. Total energy of all molecular pairs ${ }^{a}$ and the contributions of the major molecular pairs.

\begin{tabular}{|c|c|c|c|c|c|c|c|}
\hline & \multirow{2}{*}{$\begin{array}{c}\text { Total } \\
\text { energy }^{a} \\
{[\mathrm{kcal} / \mathrm{mol}]}\end{array}$} & \multicolumn{6}{|c|}{ The energy of a molecular pair } \\
\hline & & $\begin{array}{c}\text { Most stable pair } \\
\text { [kcal/mol] }\end{array}$ & $\begin{array}{l}\text { Packing } \\
\text { structure }\end{array}$ & $\begin{array}{l}\text { 2nd pair } \\
\text { [kcal/mol] }\end{array}$ & $\begin{array}{l}\text { Packing } \\
\text { structure }\end{array}$ & $\begin{array}{l}\text { 3rd pair } \\
{[\mathrm{kcal} / \mathrm{mol}]}\end{array}$ & $\begin{array}{l}\text { Packing } \\
\text { structure }\end{array}$ \\
\hline 10 & -90.2 & $\begin{array}{c}-13.3 \\
(14.7 \%)\end{array}$ & $\begin{array}{l}\text { Intra-1D } \\
\text { column }\end{array}$ & $\begin{array}{c}-12.3 \\
(13.6 \%)\end{array}$ & $\begin{array}{l}\text { Inter-1D } \\
\text { column along } \\
\text { the } c \text {-axis }\end{array}$ & $\begin{array}{c}-8.20 \\
(9.09 \%)\end{array}$ & $\begin{array}{c}\text { Phenyl ring } \\
\text { packing (face-to- } \\
\text { face) }\end{array}$ \\
\hline $2 \mathbf{Y}$ & -102.9 & $\begin{array}{l}-18.7 \\
(18.2 \%)\end{array}$ & $\begin{array}{l}\text { Intra-1D } \\
\text { column }\end{array}$ & $\begin{array}{c}-8.87 \\
(8.62 \%)\end{array}$ & $\begin{array}{c}\text { Phenyl ring } \\
\text { packing (face- } \\
\text { to-face) }\end{array}$ & $\begin{array}{c}-6.72 \\
(6.60 \%)\end{array}$ & $\begin{array}{l}\text { Inter-1D column } \\
\text { along the } c \text {-axis }\end{array}$ \\
\hline 2R & -107.6 & $\begin{array}{c}-27.8 \\
(25.8 \%)\end{array}$ & $\begin{array}{l}\text { Intra-1D } \\
\text { column }\end{array}$ & $\begin{array}{c}-6.24 \\
(5.80 \%)\end{array}$ & $\begin{array}{l}\text { Inter-1D } \\
\text { column along } \\
\text { the } c \text {-axis }\end{array}$ & $\begin{array}{c}-3.24 \\
(3.01 \%)\end{array}$ & $\begin{array}{c}\text { Phenyl ring } \\
\text { packing }\end{array}$ \\
\hline $3 \mathbf{Y}$ & -105.5 & $\begin{array}{l}-18.9 \\
(17.9 \%)\end{array}$ & $\begin{array}{l}\text { Intra-1D } \\
\text { column }\end{array}$ & $\begin{array}{c}-9.57 \\
(9.07 \%)\end{array}$ & $\begin{array}{c}\text { Phenyl ring } \\
\text { packing (face- } \\
\text { to-face) }\end{array}$ & $\begin{array}{c}-6.66 \\
(6.31 \%)\end{array}$ & $\begin{array}{l}\text { Inter-1D column } \\
\text { along the } c \text {-axis }\end{array}$ \\
\hline $3 Y O$ & -96.7 & $\begin{array}{l}-14.5 \\
(15.0 \%)\end{array}$ & $\begin{array}{l}\text { Intra-1D } \\
\text { column }\end{array}$ & $\begin{array}{c}-6.93 \\
(7.17 \%)\end{array}$ & $\begin{array}{c}\text { Inter-1D } \\
\text { column along } \\
\text { the } c \text {-axis }\end{array}$ & $\begin{array}{c}-4.86 \\
(5.03 \%)\end{array}$ & $\begin{array}{c}\text { Inter-1D column } \\
\text { related by a } \\
\text { glide plane }\end{array}$ \\
\hline 3R & -102.8 & $\begin{array}{c}-8.89 \\
(8.65 \%)\end{array}$ & $\begin{array}{l}\text { Inter-1D } \\
\text { column } \\
\text { along the } b \text { - } \\
\text { axis }\end{array}$ & $\begin{array}{c}-8.09 \\
(7.87 \%)\end{array}$ & $\begin{array}{c}\text { Inter-1D } \\
\text { column } \\
\text { related by a } \\
\text { glide plane }\end{array}$ & $\begin{array}{c}-6.42 \\
(6.67 \%)\end{array}$ & $\begin{array}{l}\text { Inter-1D column } \\
\text { along the } b \text {-axis }\end{array}$ \\
\hline $4 Y$ & -115.9 & $\begin{array}{l}-20.7 \\
(17.8 \%)\end{array}$ & $\begin{array}{l}\text { Intra-1D } \\
\text { column }\end{array}$ & $\begin{array}{l}-7.70 \\
(6.63 \%)\end{array}$ & $\begin{array}{c}\text { Phenyl ring } \\
\text { packing } \\
\text { (herring-bone) }\end{array}$ & $\begin{array}{c}-6.67 \\
(5.74 \%)\end{array}$ & $\begin{array}{l}\text { Inter-1D column } \\
\text { along the } c \text {-axis }\end{array}$ \\
\hline 50 & -135.1 & $\begin{array}{l}-15.8 \\
(11.7 \%)\end{array}$ & $\begin{array}{l}\text { Intra-1D } \\
\text { column }\end{array}$ & $\begin{array}{l}-13.9 \\
(10.3 \%)\end{array}$ & $\begin{array}{c}\text { Phenyl ring } \\
\text { packing (face- } \\
\text { to-face) }\end{array}$ & $\begin{array}{c}-12.4 \\
(9.19 \%)\end{array}$ & $\begin{array}{l}\text { Inter-1D column } \\
\text { along the } c \text {-axis }\end{array}$ \\
\hline
\end{tabular}

${ }^{a}$ The total energy of all molecular pairs is the summation of the energies of all calculated molecular pairs. A half-value of the total energy corresponds to the lattice energy. 